\title{
LA CLÁUSULA DE NO ENAJENAR EN LOS CONTRATOS DE MUTUO HIPOTECARIO
}

\section{The anti-alienation clauses in mortgage loan contracts}

\author{
Sebastián Nicolás Campos Micin* \\ Universidad de Las Américas \\ Santiago, Chile
}

RESUMEN: El presente artículo reflexiona en torno a la validez de las cláusulas de no enajenar en los contratos de mutuo hipotecario. Se revisa si, más allá del tenor del artículo 2415 del Código Civil, existe algún interés del acreedor hipotecario que pueda protegerse legítimamente mediante una de estas cláusulas. El análisis se realiza, fundamentalmente, desde la perspectiva del Código Civil y la Ley n 19.496 de 1997, en consideración que se está frente a un auténtico contrato de adhesión. El derecho de persecución, contemplado en el artículo 2428 del Código Civil, y la nulidad de las cláusulas que puedan comprenderse en el artículo 16 letra g) de la Ley $\mathrm{n}^{\circ}$ 19.496, sirven como marco de referencia del análisis. Se coordina lo planteado con las normas pertinentes del Código de Procedimiento Civil, la Ley n 18.010 , la Ley General de Bancos y el Reglamento del Registro Conservatorio de Bienes Raíces, especialmente en atención a lo establecido en el artículo 13 del Reglamento: "El Conservador no podrá rehusar ni retardar las inscripciones: deberá, no obstante, negarse, si la inscripción es en algún sentido legalmente inadmisible". Además, se reflexiona sobre los gravosos efectos que tendría la cláusula si se conjugase con una cláusula de aceleración.

PALABRAS CLAVE: Cláusulas de no enajenar, Mutuo hipotecario, Interés legítimo, Derecho de persecución, Cláusulas abusivas.

Abogado. Licenciado en Ciencias Jurídicas y Sociales, Universidad de Chile. Diplomado en Nuevas Tendencias en Daños y Contratos, Pontificia Universidad Católica de Chile. Profesor de Derecho Civil, Universidad de Las Américas. Correo electrónico: <sebastian@ abuslemepinto.cl>.

Artículo recibido el 29 de octubre de 2015 y aprobado el 7 de abril de 2016. 


\begin{abstract}
The present article reflects on the validity of anti-alienation clauses in mortgage loan contracts. We review if, beyond the wording of the article 2415 of the Chilean Civil Code, there is any interest of the mortgagee that may be protected legally through one of those clauses. The analysis is made, mostly, from the perspective of the Chilean Civil Code and the Act $n^{\circ} 19.496$, having in consideration that we are in front of an authentic contract of adhesion. The right of pursuit referred in the 2428 article of the Civil Code, and the nullity of the clauses that may be included in the article 16 letter $g$ of the Act $n^{\circ} 19496$, serve as framework of the analysis. It coordinates the issues raised with the pertinent standards of the Civil Procedure Code, the Act $n^{\circ}$ 18.010, Banks General Act of and the Regulation of the Conservatory Registry of Real State, especially in attention to what is established in article 13 of the Regulation: 'The Conservatory may not refuse or delay the enrollments: it must, however, refuse if the inscription is in any sense legally inadmissible. Also, we reflect about the burdensome effects the clause would have if combined with an acceleration clause.
\end{abstract}

KEYWORDS: Anti-alienation clauses, Mortgage loan, Legitimate interest, Right of pursuit, Abusive clauses.

\title{
I. INTRODUCCIÓN
}

No es ningún misterio que en los contratos de mutuo hipotecario se suele incorporar una cláusula del siguiente tenor: "Prohibición: El garante hipotecario se obliga a no gravar, enajenar, dar en comodato ni ceder a título alguno, ya sea gratuito u oneroso, sin previo consentimiento escrito del Banco, el inmueble individualizado en la cláusula 'Singularización Inmueble', que por el presente instrumento adquiere".

Tal fórmula, ya sea expresada de esa manera o de otra análoga, está presente en la generalidad de los contratos de mutuo hipotecario, los que, por lo demás, se otorgan usualmente en la misma escritura pública en que se celebra la compraventa del bien raíz.

No obstante, desde un punto de visto jurídico, es difícil determinar cuáles son los efectos que producirá tal cláusula (si acaso los produce), debiendo reconducirse el problema a la conocida discusión sobre la validez de la cláusula de no enajenar. ${ }^{1}$

Vodanovic et al. (1974) pp. 173-178; Peñallillo (2007) pp. 139-142. 
Por lo pronto, resulta obvio que tal cláusula no impedirá la enajenación del inmueble, pues en nuestro Código Civil existe norma expresa al respecto. En efecto, el artículo 2415 establece que "el dueño de los bienes gravados con hipoteca podrá siempre enajenarlos o hipotecarlos, no obstante cualquiera estipulación en contrario". El tenor de la norma es bastante claro y categórico: el dueño del inmueble gravado con hipoteca podrá siempre enajenar tal bien, incluso en el caso que en el contrato de mutuo hipotecario se haya establecido lo contrario. Como veremos más adelante, ninguna interpretación podría matizar esta conclusión sin contravenir derechamente los artículos 2415 y 19 del Código Civil.

Además, debe tenerse presente que, conforme a los artículos $1 \mathrm{n}^{\circ} 1,3$ inciso segundo y 17 b) y siguientes de la Ley $\mathrm{n}^{\circ} 19.496$ de 1997, que Establece Normas de Protección de los Derechos de los Consumidores (en adelante LPDC), el deudor de un mutuo hipotecario generalmente tendrá el carácter de consumidor financiero. De esta manera, atendido el interés del legislador de otorgar una protección especial a los consumidores, reflejada, por ejemplo, en los artículos 4 y 16 de la LPDC y en la diseminada regulación que la misma hace de los productos financieros y los derechos del consumidor financiero, existen razones adicionales para suponer que la cláusula de no enajenar en ningún caso impedirá la enajenación del bien raíz gravado con hipoteca, no siendo necesario siquiera el 'consentimiento escrito previo' al que se refiere la cláusula de estilo.

Precisado que la enajenación será siempre posible por parte del dueño del bien raíz, la problemática referida a la cláusula en estudio dice relación con si ésta es apta o no para producir una obligación de no hacer cuya contravención genere el derecho a demandar indemnización de perjuicios ${ }^{2}$. En otros términos, la disyuntiva que subyace a los contratos en que esté presente esta cláusula consiste en determinar si puede el Banco -y en general cualquier acreedor hipotecario- exigir indemnización de perjuicios ante la enajenación que el deudor del mutuo hipotecario haga del bien raíz gravado con hipoteca. Admitir tal posibilidad implica, en cierto sentido, estimar que efectivamente la cláusula en estudio produce efectos, por lo que, en estricto rigor, implica admitir su validez.

Con todo, desde ya adelantamos nuestra postura: la cláusula de no enajenar no genera obligación alguna en los contratos de mutuo hipotecario. En efecto, como fundamentaremos oportunamente, la referida cláusula no es válida en esta clase de contratos, pues no sirve para tutelar legítimamente

2 Vodanovic et al. (1974) p. 177. 
ningún interés; los intereses del acreedor están suficientemente amparados por el derecho de persecución contemplado en el artículo 2428 del Código Civil, por lo que la cláusula no cumple con una de sus exigencias básicas para su validez.

Se debe tener presente, además, si se estima que la cláusula genera una obligación de no hacer, que usualmente en los contratos de mutuo hipotecario existen cláusulas que permiten la aceleración de las cuotas no vencidas cuando el deudor no ha cumplido con alguna de sus obligaciones. Una de las fórmulas que puede observarse de esta cláusula es la que sigue: "Cláusula Aceleración: El Banco podrá exigir anticipadamente el pago de la totalidad del mutuo y/o declarar terminado el presente contrato y caducados todos los plazos que el deudor tenga, procediendo a su cobro, sin perjuicio de sus demás derechos como acreedor, si el Cliente y/o el garante hipotecario incurre en uno o más de los casos siguientes: b) Incumplimiento de una cualesquiera de las obligaciones de hacer o no hacer asumidas por el deudor y/o por garante hipotecario en el presente instrumento".

Por lo demás, en algunos contratos se establece derecha y expresamente que la enajenación sin previo consentimiento escrito del Banco es causal de aceleración del crédito: "Cláusula Aceleración: El Banco podrá exigir anticipadamente el pago de la totalidad del mutuo y/o declarar terminado el presente contrato y caducados todos los plazos que el deudor tenga, procediendo a su cobro, sin perjuicio de sus demás derechos como acreedor, si el Cliente y/o el garante hipotecario incurre en uno o más de los casos siguientes: f) si la parte deudora infringiere una cualquiera de las prohibiciones establecidas en la cláusula quinta del presente instrumento".

La cláusula quinta en la escritura precitada justamente señala, en relación con el bien raíz gravado con hipoteca, que "[a]simismo, la parte deudora se obliga a no enajenar ni prometer la enajenación por venta o cualquier otro título traslaticio de dominio".

Conjugada la cláusula de no enajenar y la cláusula de aceleración, podría producirse una situación bastante compleja para el deudor de un mutuo hipotecario. En efecto, si se estima que la cláusula de no enajenar genera una obligación de no hacer, e igualmente, fundado en el artículo 2415 del Código Civil, el deudor decide enajenar el bien gravado con hipoteca, las cuotas no vencidas se harían exigibles inmediatamente, pues, técnicamente, se configuraría un incumplimiento.

Como ha señalado la excelentísima Corte Suprema en Banco Santander con Aguirre (2015), en un entendimiento que a nuestro juicio es equivocado 
y pernicioso para los consumidores financieros, "el artículo 2415 sólo impide entrabar el derecho del propietario a enajenar el inmueble, pero no prohíbe que las partes, en virtud de la autonomía de la voluntad, convengan que la enajenación del bien raíz hipotecado, genere la aceleración de los dividendos no devengados del mutuo o dicho de otra forma, la exigibilidad anticipada, por la caducidad convencional del plazo, pues los contratantes son libres para estipular que ciertos hechos, futuros e inciertos, provoquen o puedan provocar la extinción anticipada del plazo".

Dado que los montos en dinero de los mutuos hipotecarios son bastante altos, merece particular atención la problemática planteada.

Por lo demás, la dilucidación respecto a la validez de la cláusula de no enajenar en los contratos de mutuo hipotecario podría aportar luces respecto a si efectivamente la caducidad convencional puede contemplar como presupuesto a la enajenación del bien raíz.

Éstos serán los temas que se tratarán en las siguientes líneas, teniendo como base normativa, fundamentalmente, las reglas pertinentes del Código Civil, de la LPDC, de la Ley $\mathrm{n}^{\circ}$ 18.010, de la Ley General de Bancos y del Reglamento del Registro Conservatorio de Bienes Raíces.

\section{Contexto del problema}

En primer lugar, a fin de analizar el problema en su contexto material, debe tenerse presente que buena parte de los contratos de mutuo hipotecario se celebran conjuntamente -esto es, en la misma escritura pública-con el contrato de compraventa que sirve de título para la adquisición del inmueble que se grava con hipoteca.

Por lo pronto, cabe preguntarse si, al menos en lo que respecta a los contratos de mutuo hipotecario celebrados entre instituciones financieras y consumidores, estamos o no en presencia de contratos de adhesión. ${ }^{3}$

En palabras de Pizarro-Wilson, podemos hablar de un contrato de adhesión cuando "el contenido del contrato está predeterminado o predispuesto de manera unilateral por el otro contratante que, de manera habitual, tiene una posición preeminente en el mercado y, en particular, respecto del otro contratante". ${ }^{4}$ En el mismo sentido, López Santa María arguye que "el

Sobre este tema, véase PizArro-Wilson et al. (2013) pp. 52-58.

Ídem., p. 54. 
contrato por adhesión es obra exclusiva del oferente, quien 'dicta' el texto de la convención. El destinatario, siendo el más débil, no puede discutir la oferta y debe circunscribirse a aceptarla". ${ }^{5}$

Es un hecho notorio que tratándose de un mutuo hipotecario el Banco predetermina de manera unilateral el contenido del contrato. El consumidor financiero, atendida su posición desmedrada en la relación, no se encuentra en condiciones de proponer cambios sustantivos al contenido del borrador. A lo sumo se le consulta si desea realizar alguna modificación al clausulado del contrato de compraventa, ya que en éste el Banco técnicamente no es parte, pero las condiciones generales y especiales del mutuo hipotecario no pueden ser alteradas.

Por lo demás, la justificación de que el Banco prepare y redacte las cláusulas del contrato no reposa solamente en el evidente desequilibrio en el poder negociador de las partes ${ }^{6}$; antes bien, reposa en la razonable pretensión, por parte de todos los intervinientes del negocio y de la economía en general, de disminuir los costos de transacción.?

En efecto, antes de la celebración de un mutuo hipotecario, los Bancos acumulan una vasta cantidad de antecedentes referidos tanto a la situación financiera y patrimonial del cliente como también a la situación del inmueble que éste último pretende adquirir. De ahí que la información de que dispone un Banco, unida a su pericia en este tipo de negocios, lo coloquen naturalmente en una posición privilegiada, pudiendo estimarse incluso que lo más eficiente es que sea éste quien prepare y redacte el borrador de escritura que contendrá el negocio. ${ }^{8}$

Sin perjuicio de lo anterior, conviene tener presente que al legislador chileno le ha preocupado la situación de la parte más débil en los contratos de adhesión, lo que queda demostrado en el reconocimiento expreso que hace de este tipo de contratos en el artículo $1^{\circ} \mathrm{n}^{\circ} 6$ de la LPDC, donde define contrato de adhesión como "aquel cuyas cláusulas han sido propuestas unilateralmente por el proveedor sin que el consumidor, para celebrarlo, pueda alterar su contenido".

López Santa María (1998) p. 108.

Ibídem.

PIZARRO-Wilson (2004) pp. 121-123.

Para un mejor aproximamiento a este tema, De LA MAZA (2003) pp. 109-148. 
En consecuencia, calificar el contrato de mutuo hipotecario como un contrato de adhesión no es una cuestión baladí, pues si se le otorga esta naturaleza, entonces el consumidor financiero estará protegido ante la existencia de cláusulas abusivas; como señala Pizarro-Wilson, "el legislador circunscribió la protección en caso de cláusulas abusivas a los contratos por adhesión". ${ }^{9}$

En efecto, debemos recordar que el artículo 16 de la LPDC establece un listado de cláusulas abusivas que no producirán efecto alguno en los contratos de adhesión.

\section{Posición del consumidor financiero en los casos de contratos de mutuo hipotecario celebrados conjuntamente con la compraventa del inmue- ble que se grava con hipoteca}

Considerando que en este trabajamos nos proponemos demostrar cómo la cláusula de no enajenar constituye una injustificada merma para el consumidor financiero, conviene tener presente cómo la escrituración típica del negocio lo coloca en una posición particularmente vulnerable no sólo respecto del mutuo hipotecario, sino también respecto de la compraventa. Atender su posición en el marco del negocio complejo que consta en la escritura pública es fundamental, pues se debe tener presente que el beneficio perseguido por el consumidor es justamente hacerse dueño del inmueble que se grava con hipoteca.

En efecto, si bien lo más eficiente es que los borradores de escritura que contienen a los contratos de compraventa y mutuo hipotecario sean elaborados por el Banco, no es menos cierto que éstos suelen favorecer mucho más al vendedor que al comprador.

¿Por qué podemos afirmar lo anterior? A este respecto conviene recordar que el artículo 2434 del Código Civil, refiriéndose al derecho real de hipoteca, señala que éste se extingue conjuntamente con la obligación principal; y la obligación principal, generada por el contrato de mutuo, esto es, la obligación de restituir el dinero prestado, se puede extinguir, entre otros modos, por nulidad o resolución, conforme a lo establecido en el artículo 1567 ns 8 y 9.

En este contexto, si por el incumplimiento de alguna de las obligaciones de las partes en la compraventa, se declarara resuelto el contrato, tal circunstancia eventualmente podría afectar la eficacia del mutuo hipotecario, el cual, además de constar en la misma escritura pública, tiene por causa, de

$9 \quad$ Pizarro-Wilson y De la Maza (2013) p. 55. 
acuerdo al artículo 1467 inciso segundo, el financiamiento de la obligación de pagar de precio. ${ }^{10}$

Así las cosas, al Banco le es conveniente que en la escritura aparezcan cumplidas todas las obligaciones emanadas del contrato de compraventa, de manera que no pueda configurarse un incumplimiento respecto a tales obligaciones y, en consecuencia, se elimine la procedencia de la resolución.

En este contexto, a fin de resguardar aún más la eficacia de un mutuo hipotecario, es usual que en la escritura se establezca la renuncia expresa de las partes a las acciones resolutorias, así como también una declaración de conformidad, en la que el comprador declara recibir satisfactoriamente el bien raíz objeto del contrato. El tenor usual de una cláusula que contemple estas declaraciones es el siguiente: "Cumplimiento De Obligaciones: La parte vendedora declara haber recibido la totalidad del precio y lo declara en consecuencia íntegramente pagado. La parte compradora declara haber recibido materialmente y a su entera satisfacción la propiedad raíz materia de este contrato. Las partes renuncian expresamente a las acciones resolutorias que pudieran emanar del presente contrato. Las partes declaran cumplida cualquier promesa de compraventa celebrada entre ellas relativa al inmueble objeto de este contrato, respecto de cuyas obligaciones se otorgan el más amplio y completo finiquito".

¿En qué le es conveniente esto al vendedor? Le es conveniente en cuanto el comprador, en tanto ha declarado recibir satisfactoriamente el bien raíz

10 Con todo, estimamos que éste es un tema complejo. Si bien el mutuo hipotecario está contenido en la misma escritura que la compraventa, técnicamente son contratos distintos e independientes. De hecho, en una escritura en la que conste una compraventa y un mutuo hipotecario pueden distinguirse al menos cuatro contratos: la compraventa, el mutuo, la hipoteca y algunos mandatos. Si se declarase la resolución de la compraventa, no por ello debiese entenderse resuelto también el mutuo ni mucho menos la hipoteca. En efecto, sin perjuicio de que, desde una perspectiva material, el consumidor que no cuenta con recursos económicos suficientes para la adquisición de un bien raíz requerirá la contratación de un mutuo hipotecario con alguna institución financiera, jurídicamente tanto la compraventa como el mutuo son contratos principales. La hipoteca, por su parte, es un contrato accesorio, pero accede al mutuo, no a la compraventa.

A nuestro juicio, la única manera de atacar la eficacia del mutuo una vez declarada resuelta la compraventa es solicitando la nulidad absoluta por falta de causa, lo que, como es evidente, conduce al problema de determinar qué se entiende por causa y si acaso ésta debe estar presente solamente al momento de la celebración del contrato o también durante su ejecución. Por lo demás, hoy en día la noción de causa está en franca decadencia. 
objeto del contrato, no podrá acudir al régimen general de remedios que le asiste ante el incumplimiento. De hecho, técnicamente, atendido el tenor del artículo 1700 del Código Civil, difícilmente podrá alegar el incumplimiento, pues en los instrumentos públicos el contenido de las declaraciones hace plena fe en contra de los declarantes.

A mayor abundamiento, si se examina el contenido de las escrituras en que constan contratos de compraventa y mutuo hipotecario, se puede observar que el único medio de tutela de que dispone el comprador es el saneamiento de la evicción, remedio cuyo ámbito de protección, si bien fundamental, es bastante acotado e improbable en la práctica, pues tanto el comprador como el Banco, en el estudio de títulos previo, han tenido la posibilidad de determinar si existen derechos reales u otros gravámenes sobre el inmueble.

En efecto, si realizado el estudio de títulos se determinase que existen derechos reales o gravámenes sobre el bien raíz, es razonable suponer que las partes no celebrarían el negocio o, si lo celebraran de igual manera, se incluiría expresamente en la escritura una cláusula que dé cuenta de tales gravámenes a fin de limitar el contenido de la obligación de saneamiento de la evicción.

La acción redhibitoria, en cambio, si bien es discutible su procedencia, también podría estimarse renunciada, básicamente por dos razones: en primer lugar, de acuerdo a la mayoría de la doctrina nacional y comparada, constituye una acción resolutoria ${ }^{11}$, por lo que, en estricto rigor, una renuncia general a las acciones resolutorias implicaría también una renuncia a la acción redhibitoria. En segundo lugar, usualmente se establece que el comprador declara aceptar y conocer el estado en que se entrega el bien raíz, por lo que, atendido el tenor del artículo $1858 \mathrm{n}^{\circ} 3$, en adición a lo que establece el artículo 1700, ambos del Código Civil, difícilmente podrá estimarse desconocido el vicio. ${ }^{12}$

11 Sobre este tema, véase Caprile (2006) pp. 642-644; De La Maza (2012) pp. 646-651. En contra, en una interesante propuesta, véase BARAONA (2008) pp. 659-668.

12 Con todo, a nuestro juicio, nada obsta a que se rinda prueba en contrario de lo declarado en la escritura pública. El principio de realidad debiese ser suficientemente poderoso para dejar sin aplicación una cláusula de estilo. Por lo demás, desde un punto de vista material, el comprador no tendrá conocimiento de los vicios redhibitorios sino desde que se hayan manifestado. No es baladí que el artículo 1866 señale que el plazo de prescripción de la acción redhibitoria se compute desde la entrega real; sólo a partir de este momento el comprador efectivamente podrá, si acaso el vicio ya está manifestado, tener conocimiento del mismo. 
Como se observa, la posición del comprador se encuentra bastante mermada en estos contratos, circunstancia que, a nuestro juicio, debe tenerse presente a la hora de analizar la validez de cláusula de no enajenar, pues ésta le puede significar una merma adicional y sustantiva del beneficio que obtiene mediante la celebración del negocio complejo, circunstancia que podría comprenderse, respecto a los consumidores financieros y únicamente en relación al mutuo hipotecario, en la hipótesis contemplada en el artículo 16 letra g) de la LDPC.

\section{VALIDEZ DE LA CLÁUSULA DE NO ENAJENAR EN LOS CONTRATOS DE MUTUO HIPOTECARIO DESDE UNA PERSPECTIVA CIVIL}

Respecto al tema de fondo, esto es, si es válida la cláusula de no enajenar en el contrato de mutuo hipotecario, conviene desde ya plantearse la siguiente paradoja: Si admitimos que tal cláusula genera una obligación de no hacer, es razonable suponer que el contenido de tal obligación consistirá en no enajenar el bien raíz. Si se relaciona tal obligación con lo establecido en el artículo 2415 del Código Civil, se observa de inmediato una contradicción. ¿Podrían las partes, lícitamente, estipular una cláusula cuyo efecto fuese generar para el consumidor financiero la obligación de no enajenar el bien raíz gravado con hipoteca y, a la vez, estimar que el dueño de tal bien -en la especie, el mismo consumidor financiero- puede enajenarlo siempre, no obstante cualquiera estipulación en contrario?

En principio, la situación planteada presenta una contradicción en sí misma. Para admitir la respuesta afirmativa habría que incurrir en una suerte de desdoblamiento y suponer que la obligación de no enajenar y el derecho irrenunciable de enajenar tienen ámbitos de aplicación distintos, lo que evidentemente no resiste mayor análisis.

Sin perjuicio de la inconsistencia revelada anteriormente, podría estimarse que el único efecto de la cláusula es generar una obligación de no hacer inoponible a terceros, cuya contravención tiene por efecto la obligación de indemnizar los perjuicios.

En palabras de Alessandri y Somarriva, "[e]l acto realizado por el infractor de la cláusula con el tercero queda perfectamente válido, porque esa cláusula es una obligación personal que no influye sino en las relaciones entre las partes que la estipularon y no sobre el acto; por la misma razón es inoponible a los terceros. Claro que el tercero adquirente de mala fe, que conocía la cláusula, puede verse obligado a devolver la cosa; pero no porque sea nulo el acto celebrado con el infractor de la cláusula, sino en virtud de la 
resolución del contrato que imponía la prohibición de enajenar, y la consiguiente reivindicación" ${ }^{\prime \prime}{ }^{13}$

No obstante, más allá de lo discutible jurídicamente que pueda resultar la tesis que se acaba de exponer ${ }^{14}$, el problema dice relación con que, desde un punto de vista práctico, se estaría igualmente limitando o gravando el derecho del consumidor financiero de enajenar el bien raíz gravado con hipoteca.

También podría estimarse que la cláusula genera una obligación reparatoria sujeta a la condición suspensiva de que se enajene el bien raíz gravado con hipoteca. En tal caso la obligación será de dar y consistirá, como es obvio, en entregar una suma de dinero en el evento de la enajenación.

Esta última tesis, además de ser bastante artificiosa, presenta el problema de que tanto la doctrina nacional como comparada estiman que la obligación de indemnizar perjuicios en materia contractual surge como una consecuencia del incumplimiento, por lo que, técnicamente, se requiere necesariamente una obligación previa que ha de ser incumplida.

En efecto, como señala Pantaleón "la responsabilidad contractual requiere, primero, que el acreedor haya sufrido un daño objetivamente imputable a la falta de cumplimiento, y segundo, que el incumplimiento sea subjetivamente imputable al deudor, esto es, que el suceso generador del mismo haya de ser puesto a cargo del deudor, conforme a la distribución de riesgos de incumplimiento expresamente pactada o deducible de las reglas contractuales, o la supletoriamente prevista por el legislador, ya de modo especial, ya en las normas generales" ${ }^{15}$

En la doctrina nacional Barros estima que "por definición, el contrato genera obligaciones de dar, hacer o no hacer (artículo 1438), que, ante todo, dan acciones de cumplimiento en naturaleza de acuerdo con las reglas de ejecución forzada del Código Civil y del Código de Procedimiento Civil. Sólo si esa obligación de primer grado no es debidamente cumplida, surge la acción de responsabilidad contractual, que tiene por objeto obtener la indemnización

\footnotetext{
13 Vodanovic et al. (1974) p. 177.

14 Podría señalarse, fundado en la operatividad del artículo 1555, que una obligación de no hacer no podría referirse nunca a la abstención de actos jurídicos, sino únicamente de hechos materiales.

15 Pantaleón (1991) p. 1043.
} 
de los daños derivados del incumplimiento total o parcial o del retardo en el cumplimiento de esa obligación principal". ${ }^{16}$

En el mismo sentido, López indica que "el fundamento de tal indemnización es el incumplimiento del contrato, porque es precisamente, como consecuencia de éste, que el acreedor ve frustrado su interés contractual" ${ }^{17}$

Con todo, si por un momento se supusiera que efectivamente la cláusula genera una obligación indemnizatoria sujeta a la condición de enajenarse el bien raíz gravado con hipoteca, cabría preguntarse cuáles serían los perjuicios que deberían ser reparados. Como sabemos, la doctrina exige que el daño sea cierto $^{18}$, y dado que el acreedor hipotecario, de acuerdo a lo establecido en el artículo 2428 del Código Civil, cuenta con derecho de persecución respecto al bien raíz gravado con hipoteca, difícilmente puede decirse que sufre una merma per se en su crédito a consecuencia de la enajenación. A lo sumo podría estimarse que constituyen perjuicios los costos en que se incurra para la tramitación de la respectiva acción de desposeimiento; no obstante, una vez realizado el bien raíz en la ejecución correspondiente, el pago deberá comprender capital, intereses y costas, de acuerdo a lo establecido en los artículos $443 n^{\circ} 2,510$ y 511, en relación con el artículo 759, todos del Código de Procedimiento Civil. Conviene tener presente, además, en caso que varios acreedores hipotecarios participen de la ejecución, lo establecido en el artículo 2472 n¹, así como también, en caso de procedimiento concursal, lo señalado en el artículo 2477 inciso cuarto.

Por lo demás, si el Banco no aplicase la cláusula de aceleración y el consumidor financiero pagase oportunamente cada cuota, en principio habría que reconocer que no existirían perjuicios, pues la enajenación en ningún sentido habría mermado el derecho de crédito del acreedor.

Ahora bien, desarrollado el punto hasta aquí, subsiste el problema de la conjugación de la cláusula de no enajenar y la cláusula de aceleración. Como señalamos en la introducción, si se estima que la cláusula de no enajenar efectivamente genera una obligación de no hacer, el Banco podría acelerar el crédito y exigir el pago de las cuotas no vencidas inmediatamente.

\footnotetext{
16 BARROS (2007) p. 978.

17 LÓPEz (2010) p. 99

18 BarRos (2007) pp. 236-240.
} 
A fin de prevenir esta situación, conviene llegar al fondo del asunto y determinar de una vez por todas si efectivamente es válida la cláusula de no enajenar establecida en un mutuo hipotecario.

Reiteramos el tenor del artículo 2415, cuya letra establece que "el dueño de los bienes gravados con hipoteca podrá siempre enajenarlos o hipotecarlos, no obstante cualquiera estipulación en contrario".

De la simple lectura, pareciera que este derecho es irrenunciable, pues, si bien el consumidor financiero podría decidir voluntariamente no enajenar el bien raíz gravado con hipoteca -configurándose una suerte de renuncia tácita-, o efectivamente obtener el consentimiento escrito previo por parte del Banco, lo cierto es que en cualquier momento podría cambiar de parecer y enajenar libremente.

En palabras de Somarriva, "para disponer del inmueble lo autoriza el artículo 2415, el cual, aún más, le reconoce esta facultad a pesar de cualquier estipulación en contrario. Si se llegara a estipular que el dueño del inmueble gravado con hipoteca no puede enajenarlo, semejante pacto, adolecería de nulidad absoluta por tener objeto ilícito (artículos 1466 y 1682) y en consecuencia la enajenación que se hiciere sería perfectamente válida e inobjetable" ${ }^{19}$

Por lo demás según varios autores, esta norma es una manifestación del principio de libre circulación de los bienes, el que, dado que atiende a un interés general, se estima de orden público. En palabras de Alessandri y Somarriva, "el principio de la libertad de disposición forma parte de un principio de orden público, el de la libertad de comercio, y constituye la regla general en nuestro derecho. Aparece consagrado en diversos preceptos del Código Civil. Así, está prohibida la constitución de dos o más fideicomisos o usufructos sucesivos (artículos 745 y 769) precisamente porque entraba la disposición de la cosa; se tiene por no escrita la cláusula de no enajenar la cosa legada, siempre que la enajenación no comprometiere ningún derecho de tercero (art. 1126); el pacto de no enajenar la cosa arrendada sólo tiene el alcance de facultar el arrendatario para permanecer en el arriendo hasta su terminación natural (art. 1964); no vale en la constitución del censo el pacto de no enajenar la finca acensuada, ni otro alguno que imponga al censuario más cargas que las expresadas en la ley (art. 2031); no obstante cualquiera

19 SOMARRIVA (1943) p. 415. 
estipulación en contrario, el dueño de los bienes gravados con hipoteca puede siempre enajenarlos o hipotecarlos (art. 2415)". ${ }^{20}$

Adicionalmente, cobra fuerza el argumento de que la facultad de disposición es el atributo que caracteriza y define al dominio, pues, desde una perspectiva material, quien se desprende de esta facultad se asimila en los hechos a un usufructuario.

Categórico es Peñailillo al sostener que "en el derecho chileno, en algunas materias específicas se prohíbe la estipulación de no enajenar (arts. 1126, $1964,2031$ y 2415$)^{\prime \prime} .^{21}$

Con todo, más allá de que se pueda considerar derechamente nula la cláusula de no enajenar en un contrato de mutuo hipotecario por contravenir una norma de orden público, conviene igualmente conceder el beneficio de la duda y analizar si se cumplen los requisitos que la doctrina mayoritaria exige para estimar válida esta cláusula en los casos en que la Ley no la ha permitido ni rechazado, a saber; por un lado, protección de un interés legítimo, $y$, por el otro, limitación en el tiempo. ${ }^{22}$

La norma que se ha tenido a la vista por esta doctrina, principalmente en lo que respecta al primer requisito, está establecida en el artículo 1.126, cuyo texto señala: "Si se lega una cosa con calidad de no enajenarla, y la enajenación no comprometiere ningún derecho de tercero, la cláusula de no enajenar se tendrá por no escrita". De ahí que, a contrario sensu, la doctrina nacional haya entendido que si la enajenación sí comprometiere un derecho o interés de un tercero, la cláusula es válida. ${ }^{23}$

Como se aprecia, la norma permitiría el establecimiento de cláusulas de no enajenar siempre y cuando mediante ellas se protegiese un derecho o interés legítimo, esto es, un interés que merezca tutela jurídica. En palabras de Alessandri y Somarriva, "siguiendo el derrotero marcado por la jurisprudencia francesa, algunos de nuestros autores aceptan las cláusulas de no enajenar relativas, esto es, aquellas que no imponen una prohibición perpetua o de largo tiempo y que se justifican por un interés legítimo. En dichos casos la temporalidad de la cláusula no embarazaría la libre circulación de los bienes que trata de garantizar la Ley, y el móvil que lleva a imponerla demostrada

\footnotetext{
20 Vodanovic et al. (1974) pp. 173 y 174.

21 Peñailillo (2007) pp. 139 y 140.

22 Vodanovic et al. (1974) pp. 176 y 177.

23 Ibídem.
} 
que no se persigue dar carácter inalienable a un bien, sino resguardar un interés legítimo" ${ }^{24}$

A su vez, Peñailillo reforzando la tesis de la validez relativa de la cláusula, señala que "[e]sta última parece ser la solución más aceptable. Con ella quedaría desvirtuado el argumento del atentado al principio de la libre circulación de los bienes que, por su naturaleza general (y no de un mero particularismo dispositivo), pareciera ser la razón más contundente para negar validez a estos pactos. En esta misma dirección, la jurisprudencia tiende a aceptar la validez de la estipulación por tiempo determinado y prudente, y con justificado motivo". ${ }^{25}$

En lo que concierne al tema que nos convoca, habrá que discernir si acaso el Banco -o acreedor hipotecario de que se trate- tiene un interés legítimo en establecer la cláusula de no enajenar. Al respecto, es fundamental tener presente que, conforme al artículo 2428 del Código Civil, el acreedor hipotecario tiene derecho de persecución: "La hipoteca da al acreedor el derecho de perseguir la finca hipotecada, sea quien fuere el que la posea, y a cualquier título que la haya adquirido".

En principio, como ya hemos enunciado, se advierte que una de las situaciones que el Banco podría querer evitar es el ejercicio, previo a la ejecución, de la acción de desposeimiento. Si consideramos que tal acción requerirá un período más o menos expedito de tramitación y que generará costos para el Banco, podríamos postular que existe aquí un interés que la cláusula de no enajenar pretende proteger.

¿El interés del acreedor hipotecario de no verse forzado a ejercer la acción de desposeimiento es susceptible de tutela jurídica mediante esta cláusula? Si bien podría estimarse que sí, debemos reiterar lo ya dicho respecto a las costas: una vez realizado el bien raíz en la ejecución correspondiente, el pago deberá comprender capital, intereses y costas.

Por lo demás, si el consumidor financiero pagase oportuna e íntegramente cada cuota vencida, ¿sería realmente legítimo, en base a lo establecido por el artículo 1546, ejercer la acción de desposeimiento?

Más allá del examen que pueda hacerse en torno al artículo 1546, estimamos que el derecho de persecución de persecución reconocido en el

\footnotetext{
$24 \quad$ Ibídem.

25 Peñailillo (2007) p. 141.
} 
artículo 2428 y el derecho a que el pago, luego de realizado el bien raíz, sea suficiente para cubrir capital, intereses y costas, son, en sentido lato, garantías suficientes para el acreedor, no pudiendo sostenerse que el interés de no verse forzado a ejercer la acción de desposeimiento sea susceptible de protección mediante una cláusula de no enajenar.

Por lo demás, el procedimiento establecido para la acción de desposeimiento en los artículos 758 y siguientes del Código de Procedimiento Civil es bastante expedito y simple.

En palabras de Somarriva, "se justifica plenamente que el legislador niegue al pacto de no enajenar que se imponga en la hipoteca, ya que la enajenación que haga el dueño del inmueble dado en garantía en nada perjudica al acreedor, porque éste en virtud del derecho de persecución de que está investido, puede hacer efectivo su derecho aún encontrándose el inmueble en manos de terceros" ${ }^{26}$

Otro interés que el Banco podría querer tutelar mediante la cláusula de no enajenar es, en conjugación con una cláusula de aceleración, la posibilidad de acelerar el crédito en caso que el inmueble haya sido enajenado. Nos parece, materialmente hablando, que éste es el meollo del asunto.

Conviene recordar el fallo de la excelentísima Corte Suprema Banco Santander con Aguirre (2015): "el artículo 2415 sólo impide entrabar el derecho del propietario a enajenar el inmueble, pero no prohíbe que las partes, en virtud de la autonomía de la voluntad, convengan que la enajenación del bien raíz hipotecado, genere la aceleración de los dividendos no devengados del mutuo o dicho de otra forma, la exigibilidad anticipada, por la caducidad convencional del plazo, pues los contratantes son libres para estipular que ciertos hechos, futuros e inciertos, provoquen o puedan provocar la extinción anticipada del plazo".

Desde ya adelantamos que discrepamos por completo de este fallo. La cuestión puede resolverse planteando el siguiente dilema: ¿Es legítimo limitar, mediante un contrato de adhesión, el derecho de dominio sobre un inmueble a fin de acelerar un crédito? Si el consumidor financiero ha mantenido en el tiempo una conducta jurídicamente correcta, pagando oportuna e íntegramente, en cada vencimiento, las cuotas en que se ha pactado el pago del dinero prestado, ¿es legítimo mermar la facultad de enajenar que le concede, irrenunciablemente, el artículo 2415, mediante la amenaza jurídica de

26 Somarriva (1943) p. 415. 
acelerar el crédito y poder cobrar todo el saldo insoluto inmediatamente? Considérese además que el saldo insoluto, generalmente, corresponderá a sumas de dinero millonarias. ¿Se ajusta esta conducta mercantil, en algún sentido siquiera, al artículo 1546, que exige que los contratos se ejecuten de buena fe?

Nos parece que, incluso desde una perspectiva puramente civil, la cláusula no resiste análisis. Creemos que, tal como ha señalado Sepúlveda ${ }^{27}$, el problema no debiese plantearse en el contexto de la enajenación del bien raíz gravado con hipoteca, sino que, en estricto rigor, debiese considerarse a la hora de que el Banco solicite la inscripción de la cláusula en el Registro de Interdicciones y Prohibiciones de Enajenar.

En efecto, el artículo 13 del Reglamento del Registro Conservatorio de Bienes Raíces establece, en lo que nos interesa, que "[e]l Conservador no podrá rehusar ni retardar las inscripciones: deberá, no obstante, negarse, si la inscripción es en algún sentido legalmente inadmisible". Si bien la norma ha dado lugar a discusiones, pues entraña el riesgo de permitir al Conservador hacer un análisis de fondo del negocio, concordamos con Sepúlveda en cuanto señala que "más que preguntarse por la admisibilidad o no de la inscripción del título traslaticio por existir una prohibición inscrita, lo que corresponde preguntarse es en qué casos es procedente que el Conservador de Bienes Raíces practique la inscripción de la prohibición voluntaria. Dicho en otros términos: ¿ puede en algunos casos ser la inscripción de la cláusula de no enajenar en algún sentido inadmisible?, al menos, en aquellos casos en que la Ley expresamente no les reconoce valor o en aquellos que de la sola lectura del título se pudiera derivar de manera clara que contraviene el orden público y, en consecuencia, adolece de nulidad absoluta". ${ }^{28}$

\section{VALIDEZ DE LA CLÁUSULA DE NO ENAJENAR EN LOS CONTRATOS DE MUTUO HIPOTECARIO DESDE LA PERSPECTIVA DE LA LEY DE PRO- TECCIÓN A LOS DERECHOS DEL CONSUMIDOR}

En la LPDC no hay ninguna norma que integre expresamente como derecho de los consumidores los derechos que otras leyes reconozcan o establezcan como irrenunciables. De ahí que, en principio, sea difícil enmarcar el problema que analizamos desde el tenor del artículo 4 de esa Ley. Tal norma señala: "Los derechos establecidos por la presente ley son irrenunciables anticipadamente por los consumidores".

\footnotetext{
27 Sepúlveda (2003).

28 Ibídem.
} 
Como puede observarse, el tenor de la norma es bastante claro, ciñéndose su aplicación únicamente a los derechos establecidos en la LPDC. Por lo demás, esta norma constituye una excepción a la regla general en derecho privado, a saber, la renunciabilidad de los derechos. Tal como señala Momberg, "es evidente que el principio de irrenunciabilidad a que se ha hecho referencia es contrario al que prevalece en el derecho privado en general, cual es justamente que los individuos pueden renunciar a sus derechos subjetivos, expresado en el artículo 12 del Código Civil, el cual establece como límites para ello el derecho de terceros y la propia Ley". ${ }^{29}$

Tratándose de la regulación que la LPDC establece respecto a los productos financieros -entre los cuales está, por supuesto, el contrato de mutuo hipotecario-, puede constatarse que la mayoría de las normas tipifican deberes de información ${ }^{30}$, sin perjuicio de que algunas establezcan derechamente prohibiciones (por ejemplo, los artículos 17 c) inciso 2,4 y 5 y 6,17 f) y 17 h).

En cuanto a los derechos que se reconocen al consumidor financiero, si bien éstos se encuentran en su mayoría establecidos en el artículo 3 inciso segundo, también existen otros regulados a lo largo de la ley. Es el caso, por ejemplo, de los derechos reconocidos en los artículos 17 d) inciso 3, 17 e) y 17 I).

En todas estas normas no se observa ninguna referencia al derecho del consumidor financiero de enajenar el bien raíz gravado con hipoteca, por lo que podría ponerse en tela de juicio si el derecho contemplado en el artículo 2415 del Código Civil es o no renunciable.

No obstante, más allá de lo ya expresado sobre el punto, si bien la regla general en derecho privado es la renunciabilidad de derechos, ello se debe a que la mayoría de sus normas son de orden privado. De ahí que, si estamos en presencia de normas de orden público, es evidente que se altera la regla contemplada en el artículo 12 del Código Civil. Como explica Momberg, "la irrenunciabilidad de un derecho generalmente se asocia con el carácter imperativo de las normas correspondientes, esto, es la imposibilidad que las partes puedan excluirlas o modificarlas al regular sus relaciones privadas". ${ }^{31}$

No hay duda, en consecuencia, de que el derecho reconocido en el artículo 2415 del Código Civil se entiende formar parte de la relación de consumo

\footnotetext{
29 Pizarro-Wilson y de La Maza (2013) p. 191.

30 Sobre la tipicidad o atipicidad de los deberes de información, véase De LA MAZA (2010) pp. 75-99.

31 Pizarro-Wilson y de La Maza (2013) p. 191.
} 
en el marco de los productos financieros. Como ya señalamos anteriormente, la doctrina ha sido clara a la hora de señalar que ésta es una norma de orden público. Tal como expresan Alessandri y Somarriva, "el principio de la libertad de disposición forma parte de un principio de orden público, el de la libertad de comercio, y constituye la regla general en nuestro derecho. Aparece consagrado en diversos preceptos del Código Civil. Así, está prohibida la constitución de dos o más fideicomisos o usufructos sucesivos (artículos 745 y 769) precisamente porque entraba la disposición de la cosa; se tiene por no escrita la cláusula de no enajenar la cosa legada, siempre que la enajenación no comprometiere ningún derecho de tercero (art. 1126); el pacto de no enajenar la cosa arrendada sólo tiene el alcance de facultar al arrendatario para permanecer en el arriendo hasta su terminación natural (art. 1964); no vale en la constitución del censo el pacto de no enajenar la finca acensuada, ni otro alguno que imponga al censuario más cargas que las expresadas en la ley (art. 2031); no obstante cualquiera estipulación en contrario, el dueño de los bienes gravados con hipoteca puede siempre enajenarlos o hipotecarlos (art. 2415)".32

Por lo tanto, si bien el artículo 4 de la LPDC establece la irrenunciabilidad de los derechos establecidos en aquella ley, parece evidente que, si el Código Civil establece ciertos derechos irrenunciables en la regulación de determinado contrato, no pueda sostenerse su renunciabilidad en el marco de una relación de consumo, sobre todo si se considera que la LPDC tiene por objeto la protección de los consumidores en el contexto de una relación de consumo.

Por otra parte, más allá del tenor literal del artículo 4, a nuestro juicio la irrenunciabilidad de los derechos establecida por la LPDC debe relacionarse con el principio de buena fe contractual, ya sea aplicado supletoriamente en virtud de lo establecido el artículo 1546 del Código Civil, ya sea materializado en la prohibición de ciertas cláusulas consideradas abusivas en la misma LPDC.

Particularmente importante nos parece el artículo 16 letra G de la LPDC, pues, si bien la doctrina estima que el establecimiento de un listado negro de cláusulas se fundamenta justamente en la buena fe contractual y el orden público económico ${ }^{33}$, la letra g) hace alusión expresa a la primera: "No producirán efecto alguno en los contratos de adhesión las cláusulas o estipulaciones que: g) En contra de las exigencias de la buena fe, atendiendo para estos efectos a parámetros objetivos, causen en perjuicio del consumidor, un desequilibrio importante en los derechos y obligaciones que para las partes se deriven del contrato. Para ello se atenderá a la finalidad del contrato y a

VoDANOVIC et al. (1974) pp. 173 y 174.

33 Sobre este tema, véase Momberg (2013) pp. 16-19. 
las disposiciones especiales o generales que lo rigen. Se presumirá que dichas cláusulas se encuentran ajustadas a exigencias de la buena fe, si los contratos a que pertenecen han sido revisados y autorizados por un órgano administrativo en ejecución de sus facultades legales". ${ }^{34}$

De esta manera, resulta claro para nosotros que la cláusula de no enajenar en un contrato de mutuo hipotecario atenta contra las exigencias de la buena fe, causando un sensible perjuicio para el consumidor financiero, materializado en un desequilibrio grave en los derechos y obligaciones de las partes. Por lo demás, el artículo 16 letra g) se remite expresamente a la finalidad y las disposiciones especiales o generales que rigen el contrato.

En efecto, conviene tener presente que "para fijar la idea de desequilibrio se otorga como guía la finalidad del contrato y a las disposiciones especiales o generales que lo rigen" ${ }^{35}$ Por lo que, en la problemática que nos ocupa, se debe tener particularmente en cuenta el artículo 2415 del Código Civil, regulado en el título XXXVIII del libro IV, denominado "De la hipoteca".

A mayor abundamiento, el consumidor financiero está obligado a restituir el dinero prestado en la forma pactada en el contrato, con todos los intereses y reajustes allí especificados, entregando, en definitiva, una suma mucho mayor a la prestada. Si tal obligación se cauciona mediante una hipoteca, el Banco contará con derecho de persecución sobre el bien raíz gravado, por lo que contará con una real seguridad para el cobro de su crédito. Por su parte, el beneficio que el mutuo hipotecario otorga al consumidor es obtener el financiamiento suficiente para adquirir un bien raíz a título oneroso -mediante la compraventa y subsecuente tradición-. Que el dominio del bien raíz se merme mediante una cláusula de no enajenar constituye evidentemente un desequilibrio importante en los derechos y obligaciones que el mutuo hipotecario genera para las partes, pues tal cláusula, conjugada con una cláusula de aceleración, sólo tiene por objeto sobre asegurar el crédito del acreedor hipotecario, disminuyendo sensiblemente el beneficio obtenido por el consumidor. Como señala la doctrina, para que nos encontremos en la hipótesis contemplada en el artículo 16 letra g) "lo relevante es la afectación a los derechos y obligaciones del consumidor, ya sea que se altera el derecho dispositivo en contra del consumidor o, desde la perspectiva de éste, se fractura el propósito práctico del contrato". ${ }^{36}$

\footnotetext{
34 Sobre los requisitos que deben cumplirse para incurrir en la causal, véase PIZARRO-WILSON y De La MaZa (2013) pp. 340-351.

35 Ídem., p. 341.

36 Pizarro-Wilson y De La Maza (2013) p. 345.
} 
Por lo demás, si el consumidor financiero pagase oportuna e íntegramente cada cuota, a su respectivo vencimiento, sería un atentado evidente a las exigencias de la buena fe que el acreedor hipotecario, fundado en la efectividad de la cláusula de no enajenar, acelere el crédito y exija inmediatamente el saldo insoluto. En tal caso, adicionalmente, habría una violación flagrante a las expectativas razonables que el consumidor financiero alberga en cuanto a una correcta y leal ejecución del contrato por parte de la institución financiera. Resulta claro que si el consumidor financiero demuestra su intención y aptitud para ejecutar cumplidamente el contrato, de manera sostenida en el tiempo, considere normal que el Banco no adopte una conducta agresiva, exigiendo la totalidad de la obligación de manera anticipada. "Esta idea de normalidad, lo esperable en la conducta del contratante, configura el estándar de lo esperado ${ }^{\prime 37}$, estándar que debe ser cumplido tanto por el Banco como por el consumidor financiero.

En palabras de Momberg y Pizarro-Wilson, "en definitiva, el examen del comportamiento del proveedor se orienta a fiscalizar si actúa en términos correctos. Se genera una ficción al considerar que el proveedor debe comportarse como un sujeto en equilibrio en la negociación. Todo lo que quede al margen de dicha conducta leal y correcta se proscribe. Se suma a esto la idea de fraude a las expectativas del consumidor que de manera razonable espera de parte del proveedor un comportamiento alejado del abuso. Son dos formas de lograr un mismo objetivo, ya sea consideramos el comportamiento ideal atribuible a un proveedor leal y respetuoso de los derechos del consumidor o, desde la perspectiva del consumidor, evaluamos si la conducta llevada a cabo por el proveedor defrauda lo que de manera legítima podría esperar un consumidor". ${ }^{38}$

Por lo demás, "ante la ausencia de un consentimiento real del consumidor o, lo que es lo mismo, la imposición del contenido del contrato, resulta valiosa la idea de confianza que debe asegurársele al consumidor por vía legislativa. La adhesión a un contenido contractual predispuesto por el proveedor viene garantizada por el amparo del mecanismo de protección sustantivo a partir de la idea de buena fe y equilibrio contractual" ${ }^{39}$

Con todo, si bien lo expresado nos parece suficientemente fuerte y operativo en la problemática que nos ocupa, quisiéramos hacernos cargo de un eventual reparo: podría aducirse que el artículo 16 letra g) está referido

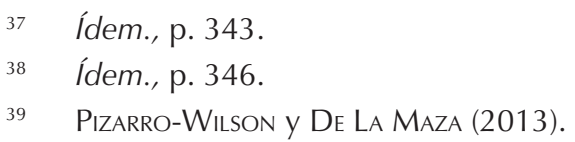


únicamente a contratos bilaterales, pues la norma exige que se cause en perjuicio del consumidor "un desequilibrio importante en los derechos y obligaciones que para las partes se deriven del contrato". El tenor de la norma podría sugerir que no es operativa tratándose de contratos unilaterales.

Postular tal tesis significaría que el artículo 16 letra g) no se aplicaría respecto a contratos de mutuo hipotecario, pues el mutuo, en base a la legislación pertinente, puede catalogarse como un contrato unilateral.

En efecto, el mutuo civil, de acuerdo a lo establecido en el artículo 2197 del Código Civil, es un contrato real, por lo que, como la mayoría de los contratos reales, únicamente genera una obligación para la parte que recibe la cosa, en este caso el mutuario.

Por su parte, el mutuo de dinero, si bien tiene una regulación especial, también puede tener el carácter de unilateral. En efecto, en base a lo que dispone el artículo $1^{\circ}$ de la Ley $n^{\circ} 18.010$ de 1981 y sus posteriores modificaciones, el mutuo de dinero puede ser unilateral o bilateral: "Son operaciones de crédito de dinero aquéllas por las cuales una de las partes entrega o se obliga a entregar una cantidad de dinero y la otra a pagarla en un momento distinto de aquel en que se celebra la convención".

Con todo, en nuestra opinión, si bien el tenor del artículo 16 letra g) es ambiguo, pues no permite distinguir claramente si se refiere sólo a contratos bilaterales o a todo contrato, la norma debe ser interpretada, en base al artículo 22 del Código Civil, en el contexto de la protección a los consumidores que la LPDC intenta otorgar. Por lo demás, si se relacionan los artículos 1439 y 578 del Código Civil, en un contrato unilateral efectivamente se genera una obligación para una parte y un derecho correlativo para la otra, por lo que, al menos desde un punto de vista lógico-formal, el tenor de la norma comprende a los contratos unilaterales.

Por otro lado, desde un punto de vista material, la norma no se fundamenta en la bilateralidad, sino en la conmutatividad del contrato.

En efecto, como señala Momberg, "se puede afirmar que tratándose de un contrato conmutativo, debe existir una cierta equivalencia entre la posición de las partes en relación con el contenido del contrato, más aún si se parte del supuesto que existe un desequilibrio estructural o posición aventajada para una de ellas, como sucede en los contratos de consumo". ${ }^{40}$

40 Momberg (2013) pp. 18 y 19. 
Por lo demás, a fin de eliminar cualquier duda, debe tenerse presente que, tratándose de mutuos hipotecarios endosables otorgados por Bancos, se torna aplicable el artículo $69 \mathrm{n}^{\circ} 7$ de la Ley General de Bancos, norma que dispone: "Los bancos podrán efectuar las siguientes operaciones: 7) Con sujeción a las normas generales que dicte la Superintendencia, los bancos podrán otorgar créditos que se encuentren amparados por garantía hipotecaria. Tales créditos se extenderán por escritura pública que lleve cláusula a la orden, de la cual se otorgará una sola copia autorizada que se entregará al acreedor, la que será transferible por endoso colocado a continuación, al margen o al dorso del documento, con indicación del nombre del cesionario. Para fines exclusivos de información, la cesión deberá anotarse al margen de la inscripción de la hipoteca". ${ }^{41}$

De esta manera, en tanto los mutuos hipotecarios comprendidos en esta norma se perfeccionan mediante escritura pública, difícilmente puede sostenerse que sean contratos unilaterales. De hecho, en la mayoría de los casos, pese a lo que formalmente pueda señalarse en alguna cláusula, la entrega efectiva del dinero prestado se realiza directamente por el Banco al vendedor, no habiendo jamás una entrega real del dinero del Banco al consumidor financiero.

Las mismas escrituras de contratos de mutuo hipotecario contienen cláusulas que señalan: "Se entenderá por 'fecha del desembolso efectivo del crédito', aquella en que el banco lo entregue al vendedor, o a quien éste haya instruido, sea mediante transferencia electrónica de fondos o mediante la emisión del correspondiente instrumento de pago".

En efecto, si bien puede declararse en la escritura que el consumidor financiero ha recibido el monto prestado por el Banco, celebrándose un mandato para que éste último entregue directamente al vendedor el dinero, los tribunales debiesen desentrañar, en el marco de contratos de adhesión, la verdadera naturaleza del negocio celebrado; una de las funciones de la LPDC consiste justamente en proteger al consumidor ante el desequilibrio que para él puede generar la forma jurídica que ostenta el negocio. En este sentido, el artículo 16 letra g) debe operar ante todo desde una perspectiva material, lo que presupone determinar la verdadera naturaleza jurídica del negocio celebrado.

Tratándose de los demás contratos de mutuo hipotecario, la verdad es que difícilmente puede sustentarse que sean contratos unilaterales, pues,

$41 \quad$ Doymarcabal (1998) pp. 204 y 205. 
en conformidad al artículo 2409 del Código Civil, la hipoteca debe constar siempre por escritura pública, y lo dicho respecto a la entrega real del dinero también es aplicable en estos casos.

Por lo demás, siguiendo en este punto a Doyharcabal, "nada se opone a que los mutuos hipotecarios sean considerados contratos bilaterales. El expreso reconocimiento por parte del mutuario de haberse realizado la tradición de las letras hipotecarias o del dinero, puede sólo significar que el mutuante ha cumplido con su obligación en forma instantánea, al momento de celebrar la convención". ${ }^{42}$

Por todo lo dicho, creemos plenamente aplicable el artículo 16 letra g) en el contexto de mutuos hipotecarios, sobre todo al considerar que el deudor tiene la calidad de consumidor financiero y que el artículo 16 letra g) constituye uno de los mecanismos más eficaces para su protección.

En palabras de Diez-Picasso, "[e]l desequilibrio en los derechos y obligaciones de las partes derivados del contrato puede concretarse contemplando, por una parte, los derechos y facultades y, por otra, las cargas y obligaciones. En el primero de los sentidos, las cláusulas serán abusivas si atribuyen al predisponente facultades de carácter exorbitante o si introducen limitaciones o restricciones injustificadas en los derechos y facultades de los consumidores.

En el segundo campo, la idea se expresa inversamente: las cláusulas serán abusivas cuando supriman o reduzcan obligaciones o responsabilidades del profesional y cuando aumenten las cargas y obligaciones del adherente" ${ }^{43}$

Finalmente, conviene tener presente lo establecido en el artículo 16 a): "Declarada la nulidad de una o varias cláusulas o estipulaciones de un contrato de adhesión, por aplicación de alguna de las normas del artículo 16, éste subsistirá con las restantes cláusulas, a menos que por la naturaleza misma del contrato, o atendida la intención original de los contratantes, ello no fuere posible. En este último caso, el juez deberá declarar nulo, en su integridad, el acto o contrato sobre el que recae la declaración".

Es evidente que declarada la nulidad de la cláusula de no enajenar en un contrato de mutuo hipotecario, éste puede subsistir con las cláusulas restantes. La naturaleza de estos contratos no lo impide en ningún sentido y no puede suponerse -al menos no con fuerza- que la intención de las partes

\footnotetext{
42 Doyharcabal (1998) p. 208.

43 Díez-Picazo y Ponce De León (2007) p 464.
} 
se ha construido fundamentalmente en torno a la cláusula de no enajenar. Como explica Pizarro-Wilson, "lo que debe considerarse es si la finalidad del contrato una vez extirpada la o las cláusulas abusivas se ve afectada, careciendo de interés persistir en la relación contractual".${ }^{44}$ Nos parece claro que la finalidad del contrato de mutuo hipotecario se cumple holgadamente una vez extirpada una cláusula de no enajenar, máxime si se considera el derecho de persecución del acreedor hipotecario establecido en el artículo 2428 del Código Civil.

\section{CONCLUSIONES}

Es un hecho que en la mayoría de los contratos de mutuo hipotecario se incluyen cláusulas de no enajenar.

Esto no deja de resultar curioso, pues el artículo 2415 del Código Civil permite al dueño del bien raíz gravado con hipoteca enajenar en cualquier momento si así lo desea, no obstante cualquier estipulación contraria.

La fórmula bajo la cual se expresa el artículo permite concluir que establece un derecho irrenunciable a favor del dueño del bien raíz gravado con hipoteca. Esta conclusión se refuerza si se considera que la norma constituye una materialización del principio de libre circulación de los bienes.

Admitir igualmente la cláusula de no enajenar supone una suerte de desdoblamiento de la realidad jurídica donde, por un lado, la ley permite al dueño del bien raíz gravado con hipoteca enajenarlo en cualquier momento, y por el otro, el contrato obliga a no enajenar.

Más allá de la contradicción que supone esta situación, conviene revisar si existe algún interés legítimo del Banco que la cláusula pueda tutelar. En este contexto, atendido que el acreedor hipotecario, en base al artículo 2428, tiene un derecho de persecución sobre la cosa en manos de quien se encuentre, no existe en principio ninguna merma a su derecho de crédito por el solo hecho de la enajenación.

Tampoco es un interés susceptible de ser tutelado mediante una cláusula de no enajenar el evitar verse forzado a ejercer la acción de desposeimiento. Si bien tal acción supondrá tiempo y costos adicionales para la realización del bien gravado con hipoteca, tales costos y esperas se verán resarcidos en tanto el pago debe comprender capital, intereses y costas, de acuerdo a lo

$44 \quad$ Pizarro-Wilson y De La Maza (2013) p. 356. 
establecido en los artículos $443 n^{\circ} 2,510$ y 511, en relación con el artículo 759, todos del Código de Procedimiento Civil.

Desde la perspectiva de la LPDC, dado que el deudor hipotecario la mayoría de las veces tendrá el carácter de consumidor financiero, tendrá aplicación lo dispuesto en el artículo 16 letra g de esa ley. Que el dominio del bien raíz se merme mediante una cláusula de no enajenar causa en perjuicio del consumidor un desequilibrio importante en los derechos y obligaciones que el contrato de compraventa y mutuo hipotecario genera para las partes, pues tal cláusula, conjugada con una cláusula de aceleración, sólo tiene por objeto sobre asegurar el crédito del acreedor hipotecario.

Tal norma no debe restringirse a los contratos bilaterales, pues su tenor, técnicamente, también permite comprender dentro de su ámbito de protección a los abusos que tengan lugar en contratos unilaterales. El artículo 578, en relación con el artículo 1439, ambos del Código Civil, nos enseña que toda obligación supone un derecho personal correlativo, por lo que perfectamente puede plantearse en los contratos unilaterales un desequilibrio importante en los derechos y obligaciones que éstos generen para las partes.

Por lo demás, el artículo 16 letra G no se fundamenta en la bilateralidad del contrato, sino en la conmutatividad del mismo y en la observancia de las exigencias de la buena fe contractual.

Por otro lado, atendidas las normas pertinentes de nuestro ordenamiento jurídico, particularmente los artículos $69 \mathrm{~N}^{\circ} 7$ de la Ley General de Bancos, 1 de la Ley 18.010 de 1981 y sus posteriores modificaciones, y 2409 del Código Civil, difícilmente puede sostenerse que los contratos de mutuo hipotecario sean unilaterales. Por lo demás, atendida la forma en que se estructura y ejecuta el negocio jurídico, sobre todo en cuanto el dinero prestado se entrega directamente al vendedor y sólo una vez que se han hecho las inscripciones en el registro conservatorio, el mutuo hipotecario aparece claramente como un contrato bilateral.

El problema que plantean las cláusulas de no enajenar en los contratos de mutuo hipotecario debiese replantearse: ya no cabe preguntarse si tales cláusulas se hacen efectivas una vez que se enajena el bien raíz gravado con hipoteca, sino si la inscripción misma de la cláusula en el registro conservatorio es en algún sentido legalmente inadmisible.

Creemos que es inadmisible en más de un solo sentido. 


\section{BIBLIOGRAFÍA CITADA}

Baraona GonzÁlez, Jorge (2008): "La acción redhibitoria como acción de nulidad", en Guzmán Brito, Alejandro (editor), Estudios de Derecho Civil III, Jornadas Nacionales de Derecho Civil Valparaíso (Santiago, Legal Publishing) pp. 659-668.

Barros Bourie, Enrique (2007): Tratado de Responsabilidad Extracontractual (Santiago, Editorial Jurídica de Chile).

Caprile BiermanN, Bruno (2006): "Las acciones del comprador insatisfecho: el cúmulo actual y la tendencia al deber de conformidad en el Derecho Comparado", Corral Talciani, Hernán y Rodríguez, María Sara (coordinadores), Estudios de Derecho Civil II (Santiago, Editorial Lexis Nexis) pp. 629-650.

De La Maza Gazmurı, Íñigo (2003): "Contratos por adhesión y cláusulas abusivas ¿Por qué el Estado y no solamente el mercado?", Revista Chilena de Derecho Privado, n 1: pp. 109-148.

(2010): "Tipicidad y atipicidad de los deberes precontractuales de información", Revista de Derecho de la Pontificia Universidad Católica de Valparaíso, n³4, pp. 75-99.

, (2012): "El régimen de los cumplimientos imperfectos en la compraventa", Revista Chilena de Derecho, vol. 39 n³, pp. 629-663.

Díez-Picazo y Ponce De León, Luis (2007): Fundamentos del Derecho Civil Patrimonial. Introducción Teoría del Contrato $\left(6^{\circ}\right.$ edición, Navarra, Thompson-Civitas).

Doyharcabal CASSE, Solange (1998): "Naturaleza jurídica del mutuo: contrato real, consensual o solemne", Revista de Derecho de la Universidad Católica de Valparaíso, n 19: pp. 199-208.

LóPeZ DíAz, Patricia (2010): "La indemnización compensatoria por incumplimiento de los contratos bilaterales como remedio autónomo en el Derecho Civil Chileno", Revista Chilena de Derecho Privado, n 15: pp. 65-113.

López Santa María, Jorge (1998): Contratos Parte General (Santiago, Editorial Jurídica, Segunda Edición Actualizada). 
Momberg URiBE, Rodrigo (2013): "El control de las cláusulas abusivas como instrumento de intervención judicial en el contrato", Revista de Derecho (Valdivia), vol. $26 \mathrm{n}^{\circ}$ 1: pp. 9-27.

PANTAleón Prieto, Fernando (1991): “El sistema de responsabilidad contractual (Materiales para un debate)", Anuario de Derecho Civil, vol. 44 n³, pp. 1019-1091.

Pañella Dı Costanzo, Renata (2012): "Análisis del contrato de mutuo hipotecario a la luz de la Ley Nº 19.496, sobre la Protección de los Derechos de los Consumidores". Disponible en: <http://derechoyconsumo. udp.cl/wp-content/uploads/2014/11/Renata-Pa\%C3\%B1ella-2012An\%C3\%A1lisis-del-contrato-de-mutuo-hipotecario.pdf>.

Peñalililo Arévalo, Daniel (2007): Los bienes, la propiedad y otros derechos reales (Santiago, Editorial Jurídica de Chile).

PizarRo-Wilson, Carlos (2004): "La eficacia del control de las cláusulas abusivas en el Derecho chileno", Revista Estudios Socio-Jurídicos, vol. 6 n ${ }^{\circ}$ 2: pp. 117-141.

Pizarro-Wilson, Carlos y De La Maza Gazmuri, íñigo (directores), barrientos CAMUS, Francisca (coordinadora) (2013): La protección de los derechos de los consumidores. Comentarios a la Ley de Protección a los Derechos de los Consumidores (Santiago, Legal Publishing Chile).

Sepúlveda Larroucau, Marco Antonio (2003): "La cláusula de no enajenar", Revista de la Corporación Chilena de Estudios de Derecho Registral, ${ }^{\circ}{ }^{\circ}$ 10 y 11. Disponible en: <http://fojasv2.conservadores.cl/articulos/index. php?10_11/articulos2>.

Somarriva Undurraga, Manuel (1943): Tratado de las cauciones (Santiago, Editorial Nascimento).

Vodanovic, Antonio, Alessandri Rodríguez, Arturo y Somarriva Undurraga, Manuel (1974): Los Bienes y los Derechos Reales (3 edición, Santiago, Editorial Nascimento). 


\section{NORMAS JURÍDICAS CITADAS}

Código Civil, Chile, Decreto con Fuerza de Ley $\mathrm{n}^{\circ} 1$ del 30 de mayo de 2000, actualizado al 22 de octubre de 2015, Fija Texto refundido, coordinado y sistematizado del Código Civil y otras leyes complementarias.

Código de Procedimiento Civil, Chile, Ley n 1.552 del 30 de agosto de 1902, actualizado al 22 de octubre de 2015.

Decreto con Fuerza de Ley $\mathrm{n}^{\circ} 3$ del 19 de diciembre de 1997, actualizado al 18 de febrero de 2015, Fija texto refundido, sistematizado y concordado de la Ley General de Bancos y de otros cuerpos legales que se indican.

Ley $\mathrm{n}^{\circ} 18.010$ de 1981, actualizada al 16 de junio de 2014, Establece normas para las operaciones de crédito y otras obligaciones de dinero que indica.

Ley $\mathrm{n}^{\circ} 19.496$ del 7 de marzo de 1997, actualizada al 23 de enero de 2016, Establece Normas de Protección de los Derechos de los Consumidores.

Reglamento del Registro Conservatorio de Bienes Raíces del 24 de junio de 1857.

\section{JURISPRUDENCIA CITADA}

Banco Santander con Aguirre (2015): Corte Suprema, 21 de abril de 2015, rol $n^{\circ} 823-2015$. 
